\title{
Uncoupled Forms of Tyrosine Hydroxylase Unmask Kinetic Isotope Effects on Chemical Steps
}

\author{
Patrick A. Frantom and Paul F. Fitzpatrick \\ Departments of Biochemistry and Biophysics and of Chemistry, Texas A\&M University, College \\ Station, Texas 77843-2128
}

Tyrosine hydroxylase (TyrH) catalyzes the hydroxylation of tyrosine to dihydroxyphenylalanine (DOPA) using $\mathrm{O}_{2}$ and a tetrahydropterin $\left(\mathrm{PH}_{4}\right)$ as cosubstrates. ${ }^{1}$ TyrH belongs to a family of aromatic amino acid hydroxylases which also includes phenylalanine hydroxylase ( $\mathrm{PheH})$ and tryptophan hydroxylase $(\operatorname{TrpH})$; all three contain virtually identical mononuclear iron sites. In the mechanism proposed for $\mathrm{TyrH}^{1 \mathrm{~b}}$ (Scheme 1), the attack on the aromatic ring by an $\mathrm{Fe}(\mathrm{IV}) \mathrm{O}$ intermediate causes a change in hybridization at the site of oxygen addition; however, no secondary isotope effect is found for wild-type TyrH when $3,5-{ }^{2} \mathrm{H}_{2}$-tyrosine is used as a substrate. ${ }^{2}$ In contrast, a ${ }^{\mathrm{D}} V_{\max }$ value of 0.93 is seen when $5-{ }^{2} \mathrm{H}$-tryptophan is used as a substrate for $\operatorname{TrpH}$, consistent with a change in hybridization in that case. ${ }^{3}$ This suggests that this chemical step in the TyrH reaction is masked by slower steps. 4,5

In wild-type $\mathrm{TyrH}$, there is a 1:1 stoichiometry between $\mathrm{PH}_{4}$ oxidation and amino acid hydroxylation. Recently, several active site mutations of TyrH have been characterized which alter this stoichiometry, such that a large excess of $\mathrm{PH}_{4}$ is consumed relative to the amount of amino acid hydroxylated. ${ }^{6}$ A kinetic model for such uncoupling is shown in Scheme $2 .{ }^{7}$ Here, TyrH binds all three substrates before the hydroxylating intermediate $(\mathrm{X})$ is formed. The reaction may then follow one of two paths, amino acid hydroxylation with $k_{1}$ as the net rate constant or unproductive breakdown of the hydroxylating intermediate with $k_{2}$ as the net rate constant. The stoichiometry of amino acid hydroxylation to $\mathrm{PH}_{4}$ oxidation, or coupling $C$, is equal to $k_{1} /\left(k_{1}+k_{2}\right)$, independently of whether slow steps precede these chemical steps. An isotope effect on $k_{1}$ will be reflected in the coupling if $k_{2} \geq k_{1}$; the magnitude of the observed isotope effect should increase to the value of the intrinsic isotope effect on $k_{1}$ as $k_{2}$ becomes much greater than $k_{1} \cdot{ }^{8}$ Consequently, isotope effects which are masked in the wild-type enzyme could be unmasked by measuring product formation for enzymes which exhibit substantial uncoupling of $\mathrm{PH}_{4}$ oxidation and tyrosine hydroxylation. In the present study, this approach has been applied to detect kinetic isotope effects on the hydroxylation of tyrosine by TyrH.

The TyrH mutant enzymes F309A, E326A, and H336E oxidize a large excess of $\mathrm{PH}_{4}$ relative to the amount of DOPA produced; for the first two enymes, the $K_{\mathrm{m}}$ values for tyrosine and 6$\mathrm{MePH}_{4}$ are changed less than 2-fold by the mutations, while both $K_{\mathrm{m}}$ values increase about 5fold in the H336E enzyme. ${ }^{6 a, c-d}$ As shown in Table 1, the ratio of DOPA formed to $\mathrm{PH}_{4}$ consumed shows a significant inverse isotope effect in the case of the F309A and E326A enzymes, while the high $K_{\mathrm{m}}$ value for 6- $\mathrm{MePH}_{4}$ of the $\mathrm{H} 336 \mathrm{E}$ enzyme results in very low precision for the isotope effect with that enzyme. The unproductive breakdown of the

E-mail: fitzpat@tamu.edu

Supporting Information Available: Derivations of eqs 1 and 2 as well as more complete equations for the isotope effects (PDF). This material is available free of charge via the Internet at http://pubs.acs.org. 
hydroxylating intermediate can also result in isotope effects on the rate of DOPA formation if the rate constant for uncoupling exceeds all other first-order rate constants in the reaction.

Consistent with this prediction, the $V_{\max }$ values for DOPA formation by the E326A and H336E enzymes show significant inverse deuterium isotope effects, while that for F309A TyrH shows a small but statistically insignificant isotope effect. Thus, use of mutant enzymes with altered product partitioning has indeed allowed unmasking of chemical steps. The magnitudes of the isotope effects are very similar to the value of 0.93 found for $\operatorname{TrpH},{ }^{3}$ supporting the proposal that all three aromatic amino acid hydroxylases share a common mechanism.

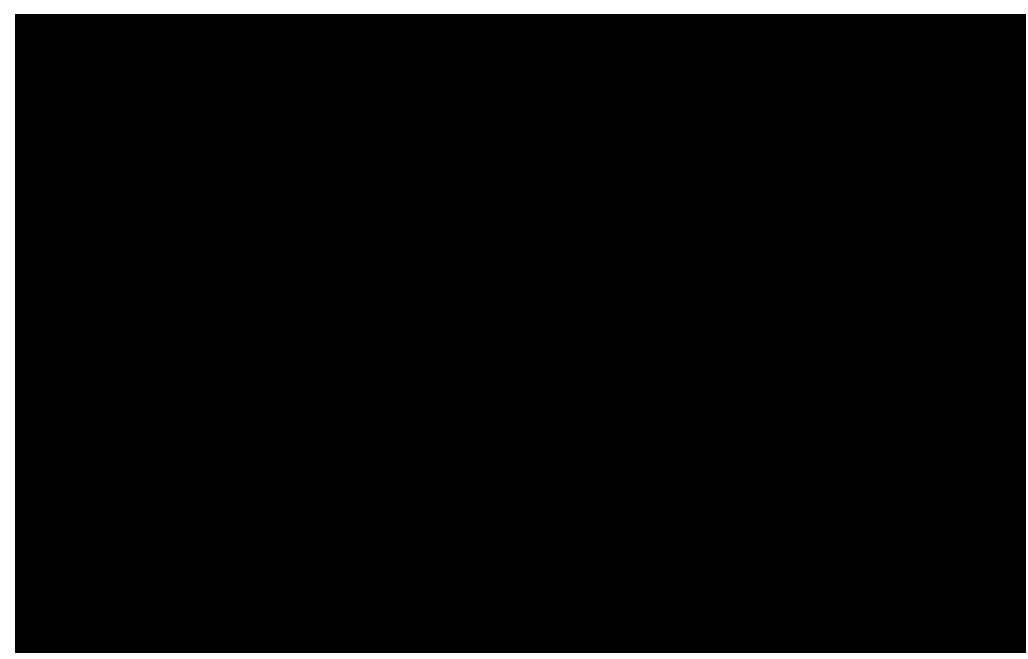

Scheme 1.

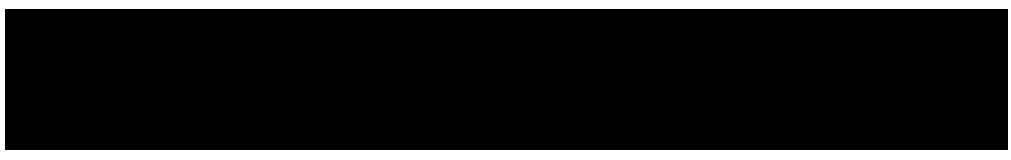

Scheme 2.

The proposed heterolytic cleavage of the peroxypterin-Fe bridge in the mechanism of Scheme 1 will require the donation of a proton. This could result in a normal solvent isotope effect on DOPA formation. The solvent isotope effects on the $V_{\max }$ values and on the coupling of DOPA formation and $\mathrm{PH}_{4}$ oxidation for the mutant enzymes are given in Table 1. While wild-type TyrH shows a solvent isotope effect of unity, ${ }^{4}$ the mutant enzymes show inverse solvent isotope effects. Figure 1 shows the proton inventory for the solvent isotope effect on the ratio of amino acid hydroxylation to $\mathrm{PH}_{4}$ oxidation. The effect on the proton inventory of a solvent isotope effect in the transition state on $k_{1}$ in Scheme 2 is given by eq 1 . A fit of the data to eq 1 yields a line which is concave up (Figure 1). Alternatively, the effect of a solvent isotope effect on $k_{2}$ is described by eq 2 . A fit of the data to eq 2 yields a significantly better fit, as shown by the straight line of Figure 1, with a solvent isotope effect in $100 \% \mathrm{D}_{2} \mathrm{O}$ of $2.38 \pm 0.04$ on $k_{2}$.

$$
\begin{gathered}
n\left(\frac{\text { aa hydroxylation }}{\mathrm{PH}_{4} \text { oxidation }}\right)=\frac{1 /\left(1-n+\left(n / \mathrm{D}_{2} \mathrm{O} k_{1}\right)\right)+k_{1} / k_{2}}{1+k_{1} / k_{2}} \\
n\left(\frac{\text { aa hydroxylation }}{\mathrm{PH}_{4} \text { oxidation }}\right)=\frac{1-n+\left(n / \mathrm{D}^{\mathrm{O}} k_{2}\right)+k_{1} / k_{2}}{1+k_{1} / k_{2}}
\end{gathered}
$$

There are two steps in Scheme 1 at which unproductive breakdown of an intermediate would result in $\mathrm{PH}_{4}$ oxidation without amino acid hydroxylation. The first possibility is breakdown 
of the peroxypterin intermediate due to protonation of the distal oxygen to form a peroxypterin. Loss of peroxide would produce a quinonoid pterin and $\mathrm{H}_{2} \mathrm{O}_{2}$. This reaction would be similar to the uncoupling of the flavin monooxygenases ${ }^{9}$ and the cytochrome $\mathrm{P} 450$ enzymes ${ }^{10}$ and to the autoxidation of tetrahydropterins. ${ }^{11}$ An alternate possibility is the unproductive decay of the putative $\mathrm{Fe}(\mathrm{IV}) \mathrm{O}$ intermediate due to attack of a water molecule. Both possibilities are consistent with the solvent inventory results. One characteristic that distinguishes breakdown of the ferryl-oxo intermediate is that the branch point occurs at the same step as amino acid hydroxylation. As shown in Figure 2, there is a good correlation between the solvent isotope effect and the secondary deuterium isotope effect for the enzymes described here, consistent with both isotope effects arising from a single step. This suggests that the uncoupled reaction of E326A TyrH is due to inappropriate access of water to the iron. The structures of TyrH and $\mathrm{PheH}$ are consistent with a role of Glu326 in preventing access of solvent to the active site. When the amino acid and $\mathrm{PH}_{4}$ are both bound to $\mathrm{PheH}$, a flexible loop moves to cover the active site. ${ }^{12}$ In the closed form, Ser137 forms a water-mediated hydrogen bond with Glu280 (Glu326 of TyrH). This serine is replaced by lysine in TyrH. Modeling of lysine in place of Ser137 in PheH shows that it could form an ionic interaction with Glu326 when the loop is closed over the active site but not when the loop is open (results not shown). This suggests that this glutamate plays a key role in keeping the active site closed, preventing access of solvent to the active site.

\section{Supplementary Material}

Refer to Web version on PubMed Central for supplementary material.

\section{Acknowledgment}

This work was funded in part by NIH grants R01-GM47291 (to P.F.F.) and T32-GM08523 (P.A.F.).

\section{References}

1. (a) Fitzpatrick PF. Annu. Rev. Biochem 1999;68:355-381. [PubMed: 10872454] (b) Fitzpatrick PF. Biochemistry 2003;42:14083-14091. [PubMed: 14640675]

2. Fitzpatrick PF. Biochemistry 1991;30:3658-3662. [PubMed: 1673058]

3. Moran GR, Derecskei-Kovacs A, Hillas PJ, Fitzpatrick PF. J. Am. Chem. Soc 2000;122:4535-4541.

4. Fitzpatrick PF. Biochemistry 1991;30:6386-6391. [PubMed: 1675871]

5. Francisco WA, Tian G, Fitzpatrick PF, Klinman JP. J. Am. Chem. Soc 1998;120:4057-4062.

6. (a) Ellis HR, Daubner SC, McCulloch RI, Fitzpatrick PF. Biochemistry 1999;38:10909-10914. [PubMed: 10460145] (b) Ellis HR, Daubner SC, Fitzpatrick PF. Biochemistry 2000;39:4174-4181. [PubMed: 10747809] (c) Daubner SC, Fitzpatrick PF. Biochemistry 1999;38:4448-4454. [PubMed: 10194366] (d) Fitzpatrick PF, Ralph EC, Ellis HR, Willmon OJ, Daubner SC. Biochemistry 2003;42:2081-8. [PubMed: 12590596]

7. Hillas PJ, Fitzpatrick PF. Biochemistry 1996;35:6969-6975. [PubMed: 8679520]

8. (a) Miwa GT, Garland WA, Hodshon BJ, Lu AYH, Northrop DB. J. Biol. Chem 1980;255:6049-6054. [PubMed: 6771263] (b) Jones JP, Korzekwa K, Rettie AE, Trager W. J. Am. Chem. Soc 1986;108:7074-7078. (c) Korzekwac KR, Trager WF, Gillette JR. Biochemistry 1989;28:9012-9018. [PubMed: 2605238]

9. Massey V. J. Biol. Chem 1994;269:22459-22462. [PubMed: 8077188]

10. Sono M, Roach MP, Coulter ED, Dawson JH. Chem. Rev 1996;96:2841-2888. [PubMed: 11848843]

11. Eberlein GA, Bruice TC, Lazarus RA, Henrie R, Benkovic SJ. J. Am. Chem. Soc 1984;106:79167924.

12. (a) Andersen OA, Flatmark T, Hough E. J. Mol. Biol 2001;314:279-291. [PubMed: 11718561] (b) Andersen OA, Flatmark T, Hough E. J. Mol. Biol 2002;320:1095-1108. [PubMed: 12126628] 


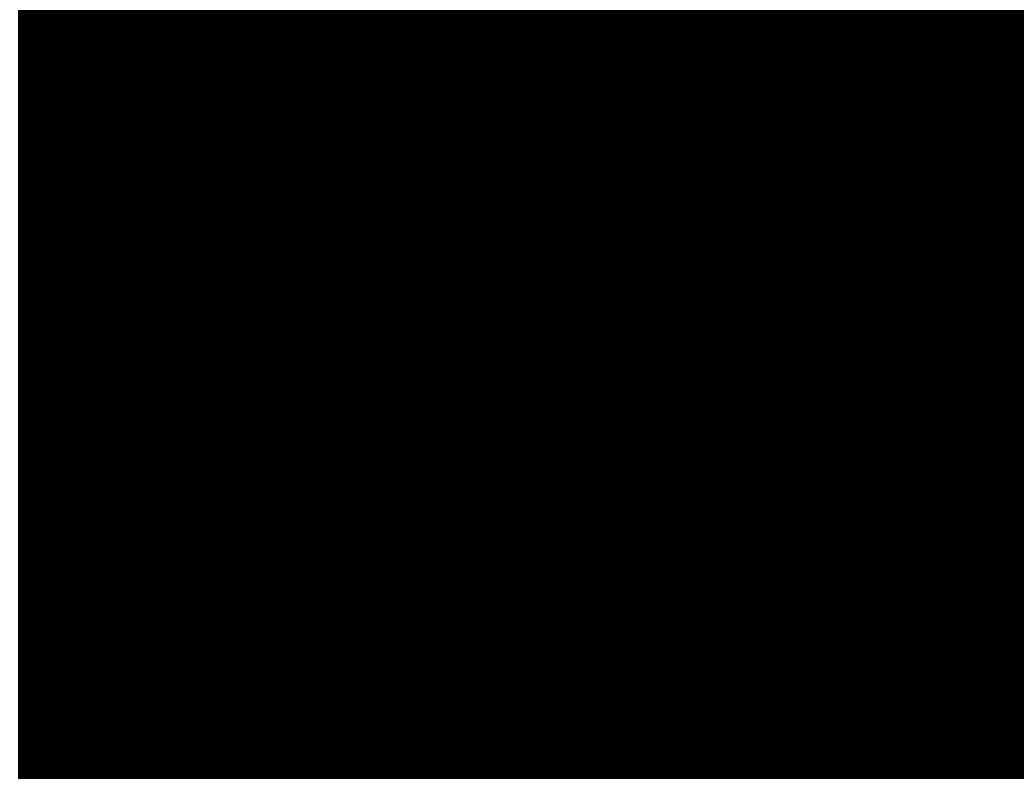

Figure 1.

Proton inventory for E326A TyrH. The curved line is from a fit of the data to eq 1; the straight line is a fit to eq 2. The relative stoichiometries of $\mathrm{PH}_{4}$ oxidation and DOPA formation were determined by HPLC as described for Table 1. Buffers were made up at $\mathrm{pH} 7.0$ and pD 7.4, the respective $\mathrm{pH}$ optima, and mixed to obtain the indicated mole ratios of $\mathrm{D}_{2} \mathrm{O}$. 


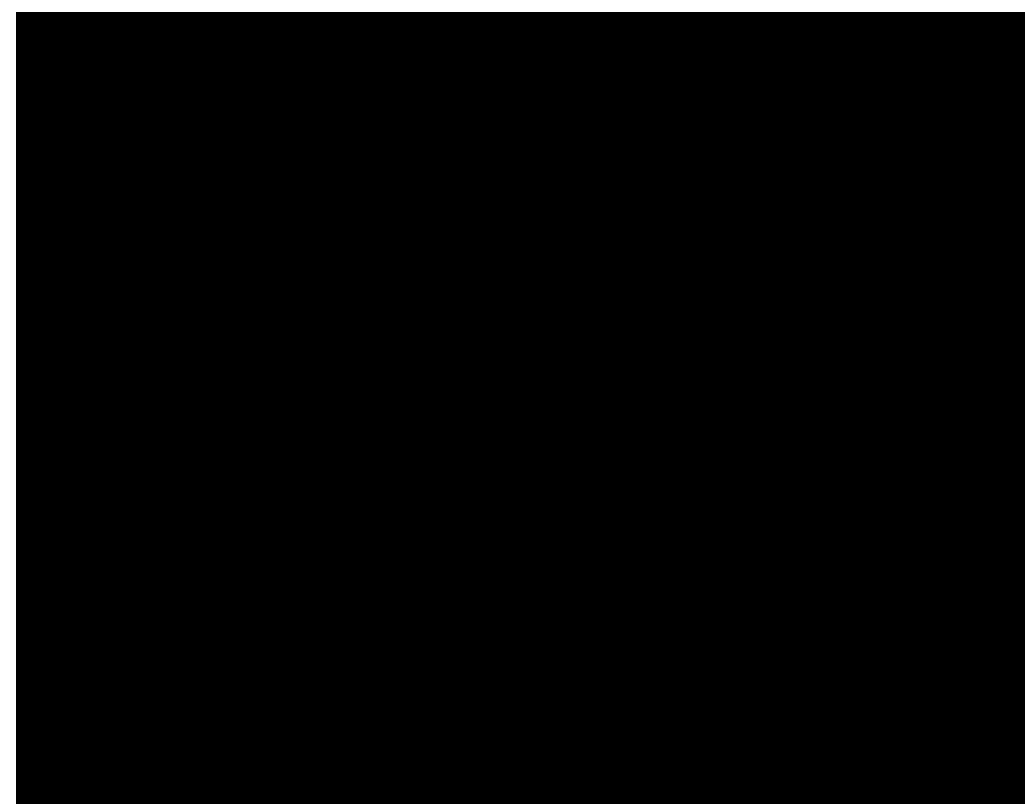

Figure 2.

Correlation between secondary and solvent isotope effects for wild-type $\mathrm{TyrH}^{2,4}$ and mutant enzymes. 


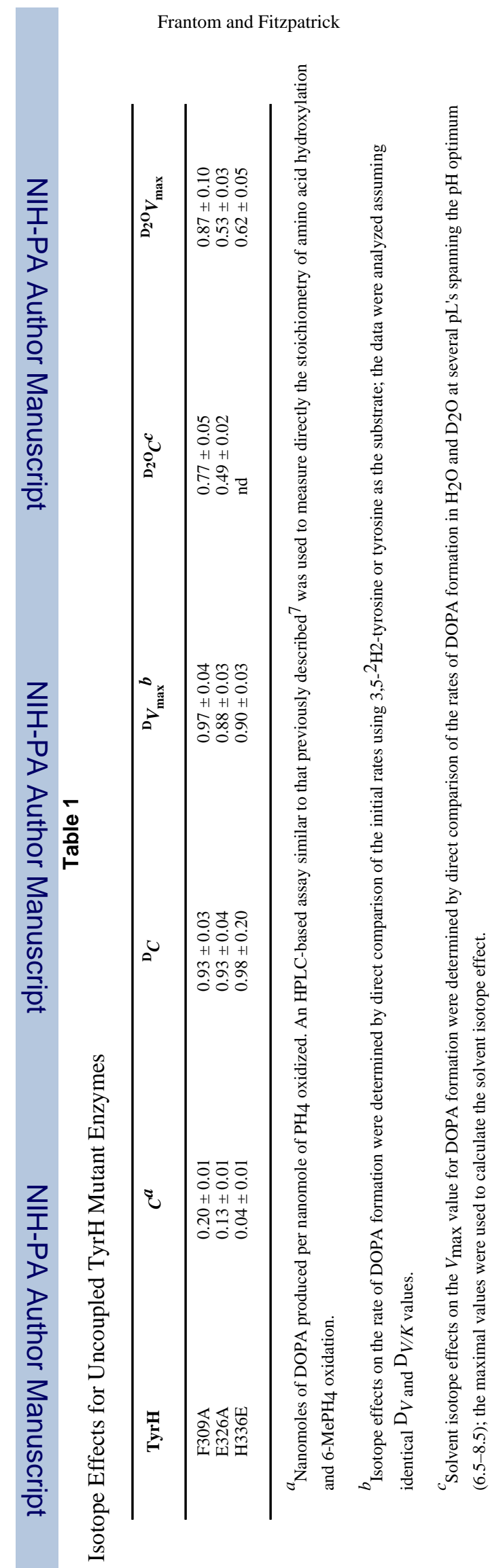

J Am Chem Soc. Author manuscript; available in PMC 2007 April 23. 